\title{
Structural Models for the KCNQ1 Voltage-Gated Potassium Channel
}

\author{
Jarrod Smith $\ddagger, \S$, Carlos G. Vanoye ${ }^{\ddagger}$, Alfred L. George Jr. ${ }^{\perp, ¥}$, Jens Meiler $§, \|, \perp,{ }^{*}$, and Charles \\ R. Sanders $\ddagger, \S$, \\ Department of Biochemistry, Center for Structural Biology, Department of Chemistry, Department \\ of Pharmacology, and Department of Medicine, Vanderbilt University, Nashville, TN 37232-8725
}

\begin{abstract}
Mutations in the human voltage-gated potassium channel KCNQ1 are associated with predisposition to deafness and various cardiac arrhythmia syndromes including congenital long QT syndrome, familial atrial fibrillation, and sudden infant death syndrome. In this work 3-D structural models were developed for both the open and closed states of human KCNQ1 to facilitate structurally-based hypotheses regarding mutation-phenotype relationships. The KCNQ1 open state was modeled using Rosetta in conjunction with Molecular Operating Environment software, and is based primarily on the recently-determined open state structure of rat $\mathrm{K}_{\mathrm{v}} 1.2$ (S.B Long et al., 2005, Science 309, 897 -903). The closed state model for KCNQ1 was developed based on the crystal structures of bacterial potassium channels and the closed state model for $\mathrm{K}_{\mathrm{v}} 1.2$ of Yarov-Yarovoy et al. (2006, Proc. Nat. Acad. Sci. 103, 7292-7207). Using the new models for KCNQ1, we generated a database for the location and predicted residue-residue interactions for more than 85 disease-linked sites in both open and closed states. These data can be used to generate structure-based hypotheses for disease phenotypes associated with each mutation. The potential utility of these models and the database is exemplified by the surprising observation that four of the five known mutations in KCNQ1 that are associated with gain-of-function KCNQ1 defects are predicted to share a common interface in the open state structure between the S1 segment of the voltage sensor in one subunit and both the S5 segment and top of the pore helix from another subunit. This interface evidently plays an important role in channel gating.
\end{abstract}

KCNQ1 is a voltage-gated potassium channel that participates critically in human physiology and is subject to several heritable disease-linked mutations (2;3). The most common splice variant of KCNQ1, also known as $\mathrm{K}_{\mathrm{v}} \mathrm{LQT1}$ or $\mathrm{K}_{\mathrm{v}} 7.1$, contains 676 residues and consists of a cytosolic $\mathrm{N}$-terminal domain followed by the voltage sensor (S1-S4), a canonical pore domain (S5-P-S6) and a long cytosolic C-terminus (see Figure 1). The best-characterized physiological function of KCNQ1 relates to its expression in cardiac tissue, where it co-assembles with

\footnotetext{
* To whom correspondence should be addressed: E-mail: jens.meiler@vanderbilt.edu, phone: 615-936-5662, fax: 615-936-2211; or chuck.sanders@ vanderbilt.edu, phone: 615-926-3756, fax: 615-936-2211..

Fepartment of Biochemistry

$\S$ Center for Structural Biology

"Department of Chemistry

$\perp_{\text {Dept. of Pharmacology }}$

${ }^{¥}$ Dept. of Medicine

Supporting Information Available

The following items are available: The Supplementary Table provides descriptions of disease-associated mutations within the open and closed state models of KCNQ1. The Supplementary Figure provide a topology plot for KCNQ1 with annotations that summarize the differences between the open and closed state KCNQ1 models with each other and with the corresponding KV1.2 structures. Protein Data Bank Format Atomic Coordinate Files are also provided for KCNQ1's open and closed state models. This material is available free of charge via the Internet at http://pubs.acs.org.
} 
KCNE1 (minK), a single transmembrane-span protein to form a channel complex that mediates the slow delayed rectifier current, $\mathrm{I}_{\mathrm{Ks}}$, a critical electrical component of the cardiac action potential necessary for myocardial repolarization (2-5).

Disruption of KCNQ1 function by dominant mutations causes more than $50 \%$ of genotypeknown cases of congenital long QT syndrome type 1 (LQTS1), a potentially fatal arrhythmic disorder(6-10). In the autosomal dominant form of the disease, Romano-Ward syndrome, mutant KCNQ1 exerts dominant-negative effects that cause loss-of-function. Recessive lossof-function mutations in KCNQ1 cause Jervell and Lange-Nielsen syndrome (JLNS), characterized by both long-QT syndrome and congenital deafness $(8 ; 9 ; 11)$. Deafness in this syndrome highlights the important role that KCNQ1 plays in tissues outside the cardiovascular system including the kidney, stomach, and ear. The association with congenital hearing loss, for example, reflects an important role for KCNQ1 channels in recycling potassium ions to reestablish transmembrane potentials following auditory stimulation in the cochlea and vestibule of the inner ear $(2 ; 11 ; 12)$. Of the spectrum of disease-causing mutations in the KCNQ1 gene, by far the most common are missense mutations that result in single amino acid residue replacements (6-9).

While LQTS1 and JLNS are the consequence of KCNQ1 mutations that induce varying degrees of loss-of-function, there are also rare mutations that result in gain-of-function $(1 ; 13-17 ; 17)$. Such mutations have been associated with familial atrial fibrillation, the short-QT syndrome, and sudden infant death syndrome (SIDS).

While several mutagenesis and electrophysiology studies have probed structure-function relationships for KCNQ1 $(2 ; 3 ; 5)$ and while a high resolution structure for one of its extramembrane domains was recently determined(18), this channel has yet to be expressed and purified in sufficient yields to be amenable to a direct structural study, limiting the degree to which disease-linked mutations in the channel domain can be structurally rationalized. The emergence of a series of experimental 3-D structures for the pore domain of related bacterial potassium channels enabled the generation of early homology-based structural models for the S5-P-S6 pore domain of KCNQ1 $(19 ; 20)$. Here, we build on previous work by using the best available crystal structure templates and state-of-the-art computational methods to develop models for both the open and closed states of KCNQ1 that include both the pore (S5-P-S6) and voltage sensor (S1-S4) domains. While these models do not represent the final word on the KCNQ1 structure, they nevertheless are useful as tools for structurally rationalizing known mutation/phenotype relationships and for generating feasible hypotheses for the mechanisms of KCNQ1 function and dysfunction.

\section{Methods}

\section{Alignment of the KCNQ1 Sequence with an Appropriate Template Sequence}

To identify the optimal template for modeling KCNQ1, the KCNQ1 sequence was submitted to a fold recognition meta server (www.bioinfo.pl) (21-23). As expected, the mammalian $\mathrm{K}_{\mathrm{v}} 1.2$ structure (PDB ID 2A79(24)) was identified as the most appropriate template for KCNQ1 model building, yielding a 3D-jury score of 85 , which is significantly better than for the best bacterial templates identified, including $\mathrm{K}_{\mathrm{v}} \mathrm{AP}(25)$. We therefore chose to use the mammalian $\mathrm{K}_{\mathrm{v}} 1.2$ template and four related mammalian protein sequences $\left(\mathrm{K}_{\mathrm{v}} 1.3\right.$ from rat and human, as well as human KCNQ2 and KCNQ5) to construct a multiple sequence alignment using BCL::Align software (Dong, Smith, and Meiler, unpublished).

BCL::Align can use a wide variety of sequence-related information such as sequence profiles and predicted secondary structure to generate multiple sequence alignments, an approach that was shown to be superior for aligning weakly homologous sequences(22). For the present 
alignment a weighted-average of the PAM250 mutation matrix(26;27) (weight: 25\%), PSIBLAST sequence profiles(28) (weight: 25\%), PSIPRED and JUFO secondary structure prediction(29-31) (weight: 15\%), and TMHMM and TMMOD transmembrane prediction (32;33) (weight: $30 \%)$ was used. The gap opening and gap extension penalties were set to -3.0 and -0.3 , respectively. These parameters were previously optimized using a small database of manually refined membrane protein alignments (Dong, Smith, and Meiler, unpublished).

The alignment is most confident in the S5-P-S6 region, where the algorithm can draw from significant sequence identity ( $\sim 38 \%$ ) in addition to secondary structure and transmembrane prediction data. Within the voltage sensor domain the sequence identity is reduced to $\sim 17 \%$. Here unambiguous alignment of each transmembrane helix (S1 through S4) relies heavily on secondary structure and transmembrane prediction data. The resulting alignment between the KCNQ1 target and $\mathrm{K}_{\mathrm{v}} 1.2$ template sequences was used for model building and is shown in Figure 1.

\section{Construction of Open and Closed State Models}

Construction of the open state model of KCNQ1 using the X-ray structure for $\mathrm{K}_{\mathrm{v}} 1.2$ as the template and the sequence alignment shown in Figure 1 is complicated by two issues. First, in the original $\mathrm{K}_{\mathrm{v}} 1.2$ open state crystal structure there are a number of residues that are not resolved in the connecting segments of S1 with S2, S2 with S3, and S3 with S4. Second, side chains were not resolved for S1 and S3 transmembrane segments and were reported in the PDB file as polyalanine segments. This missing information makes it impossible to build the KCNQ1 sequence/structure directly onto the $\mathrm{K}_{\mathrm{v}} 1.2$ scaffold for $\mathrm{S} 1$ or $\mathrm{S} 3$. However, using a hybrid method of comparative modeling and Rosetta-Membrane techniques Yarov-Yarovoy et al. addressed these issues by building the missing pieces of $\mathrm{K}_{\mathrm{v}} 1.2$ into the remainder of the structure(34). This completed $\mathrm{K}_{\mathrm{v}} 1.2$ crystal structure of the full-length open state of $\mathrm{K}_{\mathrm{v}} 1.2$ was used as the structural template for the open channel state of KCNQ1.

Because there are no experimentally-determined closed state structures of mammalian potassium channels, we used the $\mathrm{K}_{\mathrm{v}} 1.2$ closed state model of Yarov-Yarovoy et al. (34) as the template for generating the KCNQ1 closed state model. This template was built from the closed state structure of KcsA in the pore domain. For the voltage sensor domain, a hybrid approach using domain assembly and de novo protein construction was employed(34).

MOE software (Molecular Operating Environment, version 2006.08, Chemical Computing Group) was used to create initial monomer models of the open and closed states of KCNQ1. For each state, twenty candidate models were generated and scored with the MOE-Homology functionality. MOE-Homology utilizes a segment-matching procedure(35) in combination with modeling of indels based on the methods of Fechteler et al. (36) The resulting open and closed state monomer ensembles are presented in Figure 2. Four copies of the optimally-scoring candidate from each ensemble in Figure 2 were then transformed into the corresponding tetramer structure using the BIOMT records reported in the $\mathrm{K}_{\mathrm{v}} 1.2$ crystal structure using UCSF Chimera software(37). The inter-monomer interfaces of the resulting tetramer models were then optimized using Rosetta(38) to repack the side chains, followed by all-atom energy minimization with AMBER9(39) to allow for small backbone adjustments. This Rosetta/ AMBER repack/minimize cycle was repeated until the backbone conformation and AMBER energy had converged. Representatives of these refined open and closed state tetramer models are presented in Figure 3. 


\section{Results}

\section{Development and Validation of Open and Closed State Models for KCNQ1}

The development of the KCNQ1 models was highly dependent on the use of Rosetta algorithms. The Rosetta software suite is one of the best comparative modeling packages(40) as assessed in recent CASP experiments(41), particularly for cases where sequence identity is low and when flexible segments are present in the molecule of interest. Indeed, physically realistic homology models built with Rosetta can be more accurate than their experimental structural templates(42). Rosetta has recently been used to develop models for membrane protein structures $(34 ; 43)$.

Rosetta homology and de novo methods were employed to construct KCNQ1 models in the open and closed states using the open and closed state hybrid experimental/model structures (34) of $\mathrm{K}_{\mathrm{v}} 1.2$ as templates (see Methods). This approach assumes that both KCNQ1 states are similar to the corresponding states of $\mathrm{K}_{\mathrm{v}} 1.2$.

The open and closed channel models were analyzed with Procheck(44) and Maxitsoftware (http://sw-tools.pdb.org/apps/MAXIT/index.html) to assess their quality. All chiral centers were found to be correct and no close contacts $(<2.2 \AA)$ were observed. All bond lengths fell within acceptable ranges, with just 2 (open) and 4 (closed) bond angles falling outside of 6X the RMSD of dictionary values. All main chain parameter assessments (Ramachandran plot, non-bonded interactions, peptide planarity, $\mathrm{H}$-bond energies) were well within expected ranges for high-resolution structural models (2.0 ̊ or better). In the open state model, all residues fell within favored (90\%), allowed (9\%), or generously allowed (1\%) regions of the Ramachandran plot. In the closed model, only 5 residues $(0.6 \%)$ fell into disallowed regions, with the remaining $99.4 \%$ being in favored (87\%), allowed (11\%), or generously allowed (1.5\%) regions. Analysis of side chain conformations further confirmed the quality of these models with $99.7 \%$ (open) and $99.2 \%$ (closed) of $\chi_{1}$ and $\chi_{2}$ rotamers inhabiting favorable conformations. This is well within the expected bandwidth of precision for high-resolution structural models and represents a positive indicator of the reliability of these models.

The lowest energy representatives of the open and closed state ensembles were used to construct models for the channel tetramers (Figure 3). PDB files for these models are provided in the Supporting Information. Following a short energy minimization AMBER force field energies were calculated and compared to the calculated energies for the corresponding $\mathrm{K}_{\mathrm{v}} 1.2$ template structures. It was found that the open state KCNQ1 tetramer yielded a calculated energy $(-10,031 \mathrm{kCal})$ that is slightly more favorable than $\mathrm{K}_{\mathrm{v}} 1.2(-9425 \mathrm{kCa})$, with a similar result being observed for the closed state KCNQ1 $(-9364 \mathrm{kCal})$ relative to closed $\mathrm{K}_{\mathrm{v}} 1.2(-9210$ $\mathrm{kCal})$.

The results of model validation described above lend confidence to these models. Nevertheless, the limitations of the models need to be recognized and are summarized as follows.

In both open and closed state KCNQ1 models the pore domains are modeled with a higher certainty than the voltage sensor domains because of the larger number, greater completeness, and higher resolution of the available crystal structures for the pore domain, as well as because of the higher sequence identity between the $\mathrm{K}_{\mathrm{v}} 1.2$ and KCNQ1 pore domains relative to the voltage sensors. On the other hand, the extracellular loop regions of these models, which occur primarily at deletions/insertions in the sequence alignment (Figure 1), are modeled at a lower precision (Figure 2) since the conformation of these loops is based entirely on de novo methods and not on experimentally determined regions of the templates. 
The open state model is expected to be generally reliable because, except for a few short regions in the voltage sensor domain (see Methods), the entire backbone of the open state is based directly on the experimentally-determined structure of $\mathrm{K}_{\mathrm{v}} 1.2$. The closed state model, however, is based on a $\mathrm{K}_{\mathrm{v}} 1.2$ template that was itself created with a hybrid of comparative and de novo modeling techniques. Therefore, the closed state model of KCNQ1 is probably less reliable than the open state model, particularly in the voltage sensor domain. The open and closed state models in Figure 2 have been color-coded to indicate segments that are modeled directly from high resolution X-ray crystal structures, from low resolution crystal structures (with details filled in using Rosetta), or based solely on Rosetta prediction.

\section{Description of the Open and Closed State Models of KCNQ1}

The open and closed state models of KCNQ1 are illustrated in Figure 3. The topology of the models, the sequential/topological locations of the disease mutations, and key differences between KCNQ1 and $\mathrm{K}_{\mathrm{v}} 1.2$ are summarized in Figure 4 and in the Supplementary Figure. The opening and closing of the KCNQ1 pore is defined by differences in the conformation of the cytosolic-proximal segment of S6 between the open and closed states. In the closed state S6 is a nearly ideal $\alpha$-helix over its full transmembrane span, with an intrinsic tendency to kink at Pro343 being suppressed by the voltage sensor, as mediated by the downward leverage of the helical S4-S5 linker on the cytosol-proximal segment of S6 from the same subunit. The closest S6-S6 crossing point in the tetrameric closed state occurs near the cytosol-membrane interface and constricts the pore such that ions are unable to enter the inner vestibule of the channel. The channel opens because of changes in the orientation and conformation of the S1-S4 voltage sensor domain that pulls the S4-S5 linker away from the pore to release tension on S6. This permits S6 to kink at Pro343 so that its C-terminus reorients, cantilever-like, away from the central axis of the channel, opening the pore to the cytosol.

\section{Location and Interactions of Disease-Linked Mutation Sites in KCNQ1}

Disease-linked amino acid substitutions for the $>80$ channel domain sites indicated in the sequence/topology diagram of Figure 4 are listed in Supplementary Table, with a subset of 10 mutants being highlighted in Table 1. For the wild type amino acid side chains of each disease mutant site, we tabulated all amino acids that were within van der Waals contact in both the open and closed state models. We also examined the degree of solvent access to the wild type side chain in both open and closed states and have summarized electrophysiological and/or trafficking data, when available, for each mutant. As exemplified in Table 1, disease mutations in KCNQ1 can be grouped into three classes: mutations that result in gain of function, mutations that result in full or partial loss of function as a consequence of KCNQ1 misfolding and/or mistrafficking, and mutations that result in full or partial loss of function due to altered conductance or gating.

\section{Discussion}

This work has generated the first atomic-detail models for the open and closed states of KCNQ1 that include its voltage sensor domain. These structural models should, of course, be regarded as working models that are subject to revision as additional experimental structural data becomes available. Nevertheless, even with these caveats in mind, these models immediately provide intriguing and sometimes unforeseen insight into KCNQ1 channel function. This is here illustrated by two examples.

\section{Implications for Interactions of KCNE1 with KCNQ1}

While KCNQ1 functions as a voltage-gated potassium channel even in the absence of accessory subunits, its activity under physiological conditions is often profoundly modulated by KCNE1 or other members of the KCNE family of accessory proteins. Evidence indicates that KCNE1 
and KCNQ1 co-assemble early in the secretory pathway to form a complex that trafficks to the cell surface. In cardiac myocytes, this complex is responsible for $\mathrm{I}_{\mathrm{Ks}}$, a potassium current that contributes to membrane repolarization during the cardiac action potential (2-5). There is much evidence that the transmembrane and juxtamembrane cytosolic domains of KCNE1 are critical for binding to and regulating KCNQ1(4;45-47). Moreover, there is evidence that at least part of the KCNE1 transmembrane domain is in direct contact with the S6 segment of the channel(4;20;46-51), although there has been debate regarding whether the KCNE1 transmembrane domain directly participates in the ion conduction pathway.

Our models for KCNQ1 suggest that the transmembrane domain of KCNE1 may be able to directly access the S5-P-S6 domain of the channel as part of its channel modulatory function without requiring a dramatic change in the conformation of KCNQ1. Looking down onto the open and closed state models of KCNQ1 in Figures 3 and 5, clefts are observed between the voltage sensor domains through which lipids and/or proteins might be able to laterally approach the pore domain to form direct contacts with S5 and S6 segments. We have carried out simple docking calculations using both open and closed state models of the channel that confirm that there is indeed sufficient space in KCNQ1 for the transmembrane helix of an accessory protein (such as KCNE1) to fit into the clefts between voltage sensors of adjacent subunits. This does not prove that this is the functionally-relevant model of interaction between KCNE1 and KCNQ1, but does support the feasibility of such a model. Interestingly, the cleft between the voltage sensors of $\mathrm{K}_{\mathrm{V}} 1.2$ appears to be partially occluded relative to KCNQ1 (Figure 5), and this could explain why $\mathrm{K}_{\mathrm{v}} 1.2$ does not seem to be modulated by KCNE proteins $(52 ; 53)$.

\section{Structural Hypothesis for the Mechanism of Gain-of-Function Mutations}

There are five disease-associated KCNQ1 mutations that are linked to rare gain-of-function $\mathrm{I}_{\mathrm{Ks}}$ phenotypes (Figure 4 and Table 1). The Ser140Gly mutation was associated with autosomal dominant atrial fibrillation. This mutant forms $\mathrm{I}_{\mathrm{Ks}}$ channels that activate much more rapidly and generate whole-cell currents $\sim 3$ times larger than wild type $\mathrm{I}_{\mathrm{Ks}}$ channels (16). A mutation at an adjacent site, Val141Met, was also associated with familial atrial fibrillation in the context of the short-QT syndrome and exhibits a biophysical phenotype that is very similar to that observed for the Ser140Gly mutant(14). KCNQ1 Ile274Val is a mutation recently identified in sudden infant death syndrome(13). Electrophysiological studies (Rhodes, et al., manuscript submitted) indicate that the Ile274Val mutation promotes gain-of-function channel behavior that is characterized by increased $\mathrm{I}_{\mathrm{Ks}}$ whole cell currents and altered deactivation. The other two gain-of-function mutations, Ala300Thr and Val307Ile, do not result in increased current, but cause $\mathrm{I}_{\mathrm{Ks}}$ to activate more rapidly and at more negative potentials than wild type $\mathrm{I}_{\mathrm{Ks}}(1$; 17).

When the positions of these 5 gain-of-function mutations are examined in the open state channel model, 4 of these sites, Ser140, Val141, and Ile274, and Ala300 are seem to be located at the same interface between the voltage sensor from one subunit and the pore domain of another (Figure 6)footnote 2 . This is very surprising given that these 4 sites span a wide range of sequence space, representing 3 distinct segments of the channel protein. Ser140 and Val141

Footnote 2 A fifth gain-of-function mutation that is linked to short-QT syndrome, Val307Leu, is not as easy to structurally rationalize from the models as the other four. Val307Leu involves a very conservative amino acid replacement at a residue located on the P-helix. However, unlike three of the other gain-of-function mutations, when Val307Leu is co-expressed with KCNE1, there is no augmentation in the whole-cell current when compared to the wild type(1). Rather, like Ala300Thr this mutation results in gain-of-function by inducing activation at more negative potentials and by accelerating activation kinetics. From the KCNQ1 models, the Val307Ile mutation is not obviously predicted to perturb the relative energies of the open and closed states. In both open and closed models Val307 is predicted to undergo similar interactions with the S5 segment of the same subunit and to participate in an interface with the S6 of a neighboring subunit. Site 307 may play an allosteric role in modulating the voltage dependence of channel opening and to affect the transition kinetics from the closed to open state. Interestingly, there are numerous loss-of-function disease-associated mutations at sites near Ile307 in both sequential and 3-D space (see Figure 4 and Supplemental Table 1). Whether this gain-of-function mutation is truly unusual or whether, in fact, many mutations in the pore region induce channel gain-of-function but are not detected in the human population is not known. 
are located on the extracellular end of S1 and make contacts across the subunit-subunit interface with residues located near the tops of both S5 and the P-helix from a different subunit. Ile274 is located in S5 and contacts Leu137 from S1 in another subunit. Ile274 is just below the S5 contact point with sites 140 and 141 from S1. The Ile274 side chain site is also highly proximal to Ile235 and Met238 in S4. Lastly, Ala300 is located on the P-helix at the interface between S6 from the same subunit (in proximity to Ile274) and is adjacent to Ser140 and Val141 in the voltage sensor from another subunit.

The sensor/pore domain-domain interface at which these four mutations are located may help to stabilize the open channel state. Consistent with this possibility is the conservative nature of all four of these mutations. This is in sharp contrast to many loss-of-function mutations found at this interface, which typically are non-conservative substitutions that are predicted to destabilize this interface (see Supplementary Table), causing loss of function by disfavoring the open channel state or misfolding. These include: Leu137Pro (S1), Arg231His (S4), Ile235Asn (S4), Leu239Pro (S4), Phe275Ser (S5), Tyr278His (S5), Tyr281Cys (S5), and Gly306Arg (P-helix).

While the verity of the model for the voltage sensor domain and voltage sensor/pore interface of the closed state channel model is deemed to be less reliable than for the open state model, it is interesting to observe that in the closed state model (Fig. 6) the side chains for Ser140, Val141, and Ile274 are no longer predicted to be involved in intersubunit interactions, but rather appear to be lipid-exposed, which suggests that the fairly conservative gain-of-function mutations may have less of an impact on the energy of the closed channel state.

Importantly, the gain-of-function consequences of the Ser140Gly, Val141Met, and Ile274Val mutants are observed only when the channel is complexed with KCNE1(13;14;16). In the absence of KCNE1, these mutant KCNQ1 channels exhibit near-wild type channel properties. Therefore, any model explaining how these mutations induce gain-of-function must ultimately be elaborated to account for this KCNE1 dependence. While experimental data will ultimately be required to fully address this question, it should be noted that the voltage sensor-pore domain interface where these gain-of-function mutations occur sits near the base of the cleft between voltage sensor domains of adjacent subunits(see Figures 3 and 5). As noted in the above section, it seems probable that this cleft could accommodate the KCNE1 transmembrane domain and we speculate that KCNE1 participates directly in the interface between pore and voltage sensor domains.

\section{Structural Insight into Loss-of-Function KCNQ1 Mutations}

Inferring the mechanisms by which loss-of-function mutations cause reduction or complete inhibition of whole-cell $\mathrm{I}_{\mathrm{Ks}}$ currents can be difficult, even when high quality functional, trafficking, and experimental 3-D structural data in hand. Nevertheless, the cataloging of structural predictions presented in Table 1 and in the Supplementary Table for the > 80 KCNQ1 mutations associated with LQTS1 and JNLS can be employed to provide constraints that can disfavor possible structural explanations of mutant phenotypes. For example, even in the absence of detailed electrophysiological data loss-of-function due to the Ser349Trp mutation (see Table 1) seems very unlikely to be the consequence of enhanced stabilization of the closed state because the side chain of Ser349 sits at the intersubunit interface between S6 segments in the tightly constricted region of the pore (Figures 3B), where a tryptophan side chain cannot be accommodated without a major structural rearrangement in the closed state. Instead, channel loss-of-function resulting from the Ser349Trp mutation is more likely to be caused either by protein misassembly/mistrafficking or by occlusion of the pore in the normally open conformation by the bulky tryptophan side chains clustered around the mouth of the conduction pathwayfootnote 3 . Such model-derived insight does not unambiguously resolve underlying disease mechanisms, but can be used to sharpen hypotheses for the molecular biophysical basis 
of disease—insight that should prove very helpful in designing decisive functional or biochemical experiments.

\section{Conclusions}

Despite the critical importance of KCNQ1 for normal human physiology, we are aware of no progress in expressing and purifying full length KCNQ1 or its channel domain at a level that would enable the initiation of high resolution structural studies. In the absence of an experimentally-determined high resolution structure, models developed with the best available templates and computational methods can be valuable as the basis for testable hypotheses regarding mechanisms of channel function and modulation, as well as for the structural basis of disease mutation/phenotype relationships. In the case of the KCNQ1 models presented here, we are heartened by the fact that they provide an unanticipated but compelling hypothesis that a majority of known gain-of-function mutation sites are localized at the same interface between $\mathrm{S} 1$ in the voltage-sensor domain of one subunit and the S5 and P-helix segments of the pore domain of another subunit.

\section{Acknowledgements}

We thank Vladmir Yarov-Yarovoy for providing us with his models of $\mathrm{K}_{\mathrm{V}} 1.2$. We also thank Kristian Kaufmann and Elizabeth Dong for their helpful discussions and input regarding application of the Rosetta and BCL:Align methodologies and Drs. Congbao Kang and Changlin Tian for help with figures and docking calculations.

This study was supported by NIH grants R01 DC007416 (CRS) and HL077188 (ALG).

\section{Footnote 1. Abbreviations}

$\mathrm{AF}$, atrial fibrillation

DN, dominant negative

E1, the KCNE1 protein

JLNS, Jervell and Lange-Nielsen syndrome

LQTS1, long-QT syndrome, type 1

P-helix, pore helix

Q1, the KCNQ1 protein

RMSD, root-mean-squared deviation

RWS, Romano-Ward syndrome (autosomal dominant LQTS1)

SIDS, sudden infant death syndrome

WT, wild type

\section{References}

1. Bellocq C, van Ginneken AC, Bezzina CR, Alders M, Escande D, Mannens MM, Baro I, Wilde AA. Mutation in the KCNQ1 gene leading to the short QT-interval syndrome. Circulation 2004;109:23942397. [PubMed: 15159330]

2. Jespersen T, Grunnet M, Olesen SP. The KCNQ1 potassium channel: from gene to physiological function. Physiology. (Bethesda.) 2005;20:408-416. [PubMed: 16287990]

3. Robbins J. KCNQ potassium channels: physiology, pathophysiology, and pharmacology. Pharmacol. Ther 2001;90:1-19. [PubMed: 11448722]

4. McCrossan ZA, Abbott GW. The MinK-related peptides. Neuropharmacology 2004;47:787-821. [PubMed: 15527815]

5. Tristani-Firouzi M, Sanguinetti MC. Structural determinants and biophysical properties of HERG and KCNQ1 channel gating. J. Mol. Cell Cardiol 2003;35:27-35. [PubMed: 12623297]

Footnote 3 It should be kept in mind that under heterozygous WT/mutant KCNQ1 allele conditions, a given KCNQ1 tetramer might include anywhere from $0-4$ mutant subunits. 
6. Herbert E, Trusz-Gluza M, Moric E, Smilowska-Dzielicka E, Mazurek U, Wilczok T. KCNQ1 gene mutations and the respective genotype-phenotype correlations in the long QT syndrome. Med. Sci. Monit 2002;8:RA240-RA248. [PubMed: 12388934]

7. Napolitano C, Priori SG, Schwartz PJ, Bloise R, Ronchetti E, Nastoli J, Bottelli G, Cerrone M, Leonardi S. Genetic testing in the long QT syndrome: development and validation of an efficient approach to genotyping in clinical practice. JAMA 2005;294:2975-2980. [PubMed: 16414944]

8. Schwartz PJ, Priori SG, Spazzolini C, Moss AJ, Vincent GM, Napolitano C, Denjoy I, Guicheney P, Breithardt G, Keating MT, Towbin JA, Beggs AH, Brink P, Wilde AA, Toivonen L, Zareba W, Robinson JL, Timothy KW, Corfield V, Wattanasirichaigoon D, Corbett C, Haverkamp W, SchulzeBahr E, Lehmann MH, Schwartz K, Coumel P, Bloise R. Genotype-phenotype correlation in the longQT syndrome: gene-specific triggers for life-threatening arrhythmias. Circulation 2001;103:89-95. [PubMed: 11136691]

9. Splawski I, Tristani-Firouzi M, Lehmann MH, Sanguinetti MC, Keating MT. Mutations in the hminK gene cause long QT syndrome and suppress IKs function. Nat. Genet 1997;17:338-340. [PubMed: 9354802]

10. Tester DJ, Will ML, Haglund CM, Ackerman MJ. Compendium of cardiac channel mutations in 541 consecutive unrelated patients referred for long QT syndrome genetic testing. Heart Rhythm 2005;2:507-517. [PubMed: 15840476]

11. Peters TA, Monnens LA, Cremers CW, Curfs JH. Genetic disorders of transporters/channels in the inner ear and their relation to the kidney. Pediatr. Nephrol 2004;19:1194-1201. [PubMed: 15365806]

12. Willems PJ. Genetic causes of hearing loss. N. Engl. J. Med 2000;342:1101-1109. [PubMed: 10760311]

13. Arnestad M, Crotti L, Rognum TO, Insolia R, Pedrazzini M, Ferrandi C, Vege A, Wang DW, Rhodes TE, George AL Jr. Schwartz PJ. Prevalence of long-QT syndrome gene variants in sudden infant death syndrome. Circulation 2007;115:361-367. [PubMed: 17210839]

14. Hong K, Piper DR, az-Valdecantos A, Brugada J, Oliva A, Burashnikov E, Santos-de-Soto J, GruesoMontero J, az-Enfante E, Brugada P, Sachse F, Sanguinetti MC, Brugada R. De novo KCNQ1 mutation responsible for atrial fibrillation and short QT syndrome in utero. Cardiovasc. Res 2005;68:433-440. [PubMed: 16109388]

15. Schwartz PJ, Priori SG, Bloise R, Napolitano C, Ronchetti E, Piccinini A, Goj C, Breithardt G, Schulze-Bahr E, Wedekind H, Nastoli J. Molecular diagnosis in a child with sudden infant death syndrome. Lancet 2001;358:1342-1343. [PubMed: 11684219]

16. Chen YH, Xu SJ, Bendahhou S, Wang XL, Wang Y, Xu WY, Jin HW, Sun H, Su XY, Zhuang QN, Yang YQ, Li YB, Liu Y, Xu HJ, Li XF, Ma N, Mou CP, Chen Z, Barhanin J, Huang W. KCNQ1 gain-of-function mutation in familial atrial fibrillation. Science 2003;299:251-254. [PubMed: 12522251]

17. Bianchi L, Priori SG, Napolitano C, Surewicz KA, Dennis AT, Memmi M, Schwartz PJ, Brown AM. Mechanisms of I(Ks) suppression in LQT1 mutants. Am. J. Physiol Heart Circ. Physiol 2000;279:H3003-H3011. [PubMed: 11087258]

18. Howard RJ, Clark KA, Holton JM, Minor DL Jr. Structural insight into KCNQ (Kv7) channel assembly and channelopathy. Neuron 2007;53:663-675. [PubMed: 17329207]

19. Du LP, Li MY, Tsai KC, You QD, Xia L. Characterization of binding site of closed-state KCNQ1 potassium channel by homology modeling, molecular docking, and pharmacophore identification. Biochem. Biophys. Res. Commun 2005;332:677-687. [PubMed: 15904893]

20. Tapper AR, George AL Jr. Location and orientation of minK within the $\mathrm{I}(\mathrm{Ks})$ potassium channel complex. J. Biol. Chem 2001;276:38249-38254. [PubMed: 11479291]

21. Bujnicki JM, Elofsson A, Fischer D, Rychlewski L. Structure prediction meta server. Bioinformatics 2001;17:750-751. [PubMed: 11524381]

22. Ginalski K, Elofsson A, Fischer D, Rychlewski L. 3D-Jury: a simple approach to improve protein structure predictions. Bioinformatics 2003;19:1015-1018. [PubMed: 12761065]

23. Lundstrom J, Rychlewski L, Bujnicki J, Elofsson A. Pcons: a neural-network-based consensus predictor that improves fold recognition. Protein Sci 2001;10:2354-2362. [PubMed: 11604541]

24. Long SB, Campbell EB, Mackinnon R. Crystal structure of a mammalian voltage-dependent Shaker family K+ channel. Science 2005;309:897-903. [PubMed: 16002581] 
25. Jiang Y, Lee A, Chen J, Ruta V, Cadene M, Chait BT, Mackinnon R. X-ray structure of a voltagedependent K+ channel. Nature 2003;423:33-41. [PubMed: 12721618]

26. Barker WC, Ketcham LK, Dayhoff MO. A comprehensive examination of protein sequences for evidence of internal gene duplication. J. Mol. Evol 1978;10:265-281. [PubMed: 633380]

27. Dayhoff MO, Orcutt BC. Methods for identifying proteins by using partial sequences. Proc. Natl. Acad. Sci. U. S. A 1979;76:2170-2174. [PubMed: 287054]

28. Altschul SF, Madden TL, Schaffer AA, Zhang J, Zhang Z, Miller W, Lipman DJ. Gapped BLAST and PSI-BLAST: a new generation of protein database search programs. Nucleic Acids Res 1997;25:3389-3402. [PubMed: 9254694]

29. Meiler J, Muller M, Zeidler A, Schmaschke F. Generation and evaluation of dimension-reduced amino acid parameter representations by artificial neural networks. Journal of Molecular Modeling 2001;7:360-369.

30. Meiler J, Baker D. Coupled prediction of protein secondary and tertiary structure. Proc. Natl. Acad. Sci. U. S. A 2003;100:12105-12110. [PubMed: 14528006]

31. Jones DT. Protein secondary structure prediction based on position-specific scoring matrices. J. Mol. Biol 1999;292:195-202. [PubMed: 10493868]

32. Kahsay RY, Gao G, Liao L. An improved hidden Markov model for transmembrane protein detection and topology prediction and its applications to complete genomes. Bioinformatics 2005;21:18531858. [PubMed: 15691854]

33. Sonnhammer EL, von HG, Krogh A. A hidden Markov model for predicting transmembrane helices in protein sequences. Proc. Int. Conf. Intell. Syst. Mol. Biol 1998;6:175-182. [PubMed: 9783223]

34. Yarov-Yarovoy V, Baker D, Catterall WA. Voltage sensor conformations in the open and closed states in ROSETTA structural models of $\mathrm{K}(+)$ channels. Proc. Natl. Acad. Sci. U. S. A 2006;103:7292-7297. [PubMed: 16648251]

35. Levitt M. Accurate modeling of protein conformation by automatic segment matching. J. Mol. Biol 1992;226:507-533. [PubMed: 1640463]

36. Fechteler T, Dengler U, Schomburg D. Prediction of protein three-dimensional structures in insertion and deletion regions: a procedure for searching data bases of representative protein fragments using geometric scoring criteria. J. Mol. Biol 1995;253:114-131. [PubMed: 7473707]

37. Pettersen EF, Goddard TD, Huang CC, Couch GS, Greenblatt DM, Meng EC, Ferrin TE. UCSF Chimera--a visualization system for exploratory research and analysis. J. Comput. Chem 2004;25:1605-1612. [PubMed: 15264254]

38. Kuhlman B, Baker D. Native protein sequences are close to optimal for their structures. Proc. Natl. Acad. Sci. U. S. A 2000;97:10383-10388. [PubMed: 10984534]

39. Case DA, Cheatham TE III, Darden T, Gohlke H, Luo R, Merz KM Jr. Onufriev A, Simmerling C, Wang B, Woods RJ. The Amber biomolecular simulation programs. J. Comput. Chem 2005;26:16681688. [PubMed: 16200636]

40. Rohl CA, Strauss CE, Chivian D, Baker D. Modeling structurally variable regions in homologous proteins with rosetta. Proteins 2004;55:656-677. [PubMed: 15103629]

41. Chivian D, Kim DE, Malmstrom L, Schonbrun J, Rohl CA, Baker D. Prediction of CASP6 structures using automated Robetta protocols. Proteins 2005;61(Suppl 7):157-166. [PubMed: 16187358]

42. Misura KM, Chivian D, Rohl CA, Kim DE, Baker D. Physically realistic homology models built with ROSETTA can be more accurate than their templates. Proc. Natl. Acad. Sci. U. S. A 2006;103:53615366. [PubMed: 16567638]

43. Yarov-Yarovoy V, Schonbrun J, Baker D. Multipass membrane protein structure prediction using Rosetta. Proteins 2006;62:1010-1025. [PubMed: 16372357]

44. Laskowski RA, Macarthur MW, Moss DS, Thornton JM. Procheck - A Program to Check the Stereochemical Quality of Protein Structures. Journal of Applied Crystallography 1993;26:283-291.

45. Rocheleau JM, Gage SD, Kobertz WR. Secondary structure of a KCNE cytoplasmic domain. J. Gen. Physiol 2006;128:721-729. [PubMed: 17130521]

46. Tapper AR, George AL Jr. MinK subdomains that mediate modulation of and association with KvLQT1. J. Gen. Physiol 2000;116:379-390. [PubMed: 10962015] 
47. Gage SD, Kobertz WR. KCNE3 truncation mutants reveal a bipartite modulation of KCNQ1 K+ channels. J. Gen. Physiol 2004;124:759-771. [PubMed: 15572349]

48. Chen H, Kim LA, Rajan S, Xu S, Goldstein SA. Charybdotoxin binding in the I(Ks) pore demonstrates two MinK subunits in each channel complex. Neuron 2003;40:15-23. [PubMed: 14527430]

49. Melman YF, Domenech A, de la LS, McDonald TV. Structural determinants of KvLQT1 control by the KCNE family of proteins. J. Biol. Chem 2001;276:6439-6444. [PubMed: 11104781]

50. Melman YF, Um SY, Krumerman A, Kagan A, McDonald TV. KCNE1 binds to the KCNQ1 pore to regulate potassium channel activity. Neuron 2004;42:927-937. [PubMed: 15207237]

51. Panaghie G, Tai KK, Abbott GW. Interaction of KCNE subunits with the KCNQ1 K+ channel pore. J. Physiol 2006;570:455-467. [PubMed: 16308347]

52. Grunnet M, Jespersen T, Rasmussen HB, Ljungstrom T, Jorgensen NK, Olesen SP, Klaerke DA. KCNE4 is an inhibitory subunit to the KCNQ1 channel. J. Physiol 2002;542:119-130. [PubMed: 12096056]

53. Grunnet M, Rasmussen HB, Hay-Schmidt A, Rosenstierne M, Klaerke DA, Olesen SP, Jespersen T. KCNE4 is an inhibitory subunit to Kv1.1 and Kv1.3 potassium channels. Biophys. J 2003;85:15251537. [PubMed: 12944270]

54. Splawski I, Shen J, Timothy KW, Lehmann MH, Priori S, Robinson JL, Moss AJ, Schwartz PJ, Towbin JA, Vincent GM, Keating MT. Spectrum of mutations in long-QT syndrome genes. KVLQT1, HERG, SCN5A, KCNE1, and KCNE2. Circulation 2000;102:1178-1185. [PubMed: 10973849]

55. Hong K, Piper DR, az-Valdecantos A, Brugada J, Oliva A, Burashnikov E, Santos-de-Soto J, GruesoMontero J, az-Enfante E, Brugada P, Sachse F, Sanguinetti MC, Brugada R. De novo KCNQ1 mutation responsible for atrial fibrillation and short QT syndrome in utero. Cardiovasc. Res 2005;68:433-440. [PubMed: 16109388]

56. Priori SG, Barhanin J, Hauer RN, Haverkamp W, Jongsma HJ, Kleber AG, McKenna WJ, Roden DM, Rudy Y, Schwartz K, Schwartz PJ, Towbin JA, Wilde AM. Genetic and molecular basis of cardiac arrhythmias: impact on clinical management parts I and II. Circulation 1999;99:518-528. [PubMed: 9927398]

57. Wang Z, Tristani-Firouzi M, Xu Q, Lin M, Keating MT, Sanguinetti MC. Functional effects of mutations in KvLQT1 that cause long QT syndrome. J. Cardiovasc. Electrophysiol 1999;10:817826. [PubMed: 10376919]

58. Huang L, Bitner-Glindzicz M, Tranebjaerg L, Tinker A. A spectrum of functional effects for disease causing mutations in the Jervell and Lange-Nielsen syndrome. Cardiovasc. Res 2001;51:670-680. [PubMed: 11530100]

59. Wilson AJ, Quinn KV, Graves FM, Bitner-Glindzicz M, Tinker A. Abnormal KCNQ1 trafficking influences disease pathogenesis in hereditary long QT syndromes (LQT1). Cardiovasc. Res 2005;67:476-486. [PubMed: 15935335]

60. Tranebjaerg L, Bathen J, Tyson J, Bitner-Glindzicz M. Jervell and Lange-Nielsen syndrome: a Norwegian perspective. Am. J. Med. Genet 1999;89:137-146. [PubMed: 10704188]

61. Priori SG, Schwartz PJ, Napolitano C, Bianchi L, Dennis A, De FM, Brown AM, Casari G. A recessive variant of the Romano-Ward long-QT syndrome? Circulation 1998;97:2420-2425. [PubMed: 9641694]

62. Chouabe C, Neyroud N, Guicheney P, Lazdunski M, Romey G, Barhanin J. Properties of KvLQT1 $\mathrm{K}+$ channel mutations in Romano-Ward and Jervell and Lange-Nielsen inherited cardiac arrhythmias. EMBO J 1997;16:5472-5479. [PubMed: 9312006]

63. Neyroud N, Denjoy I, Donger C, Gary F, Villain E, Leenhardt A, Benali K, Schwartz K, Coumel P, Guicheney P. Heterozygous mutation in the pore of potassium channel gene KvLQT1 causes an apparently normal phenotype in long QT syndrome. Eur. J. Hum. Genet 1998;6:129-133. [PubMed: 9781056]

64. Seebohm G, Scherer CR, Busch AE, Lerche C. Identification of specific pore residues mediating KCNQ1 inactivation. A novel mechanism for long QT syndrome. J. Biol. Chem 2001;276:13600 13605. [PubMed: 11278406] 


\section{Supplementary Material}

Refer to Web version on PubMed Central for supplementary material. 


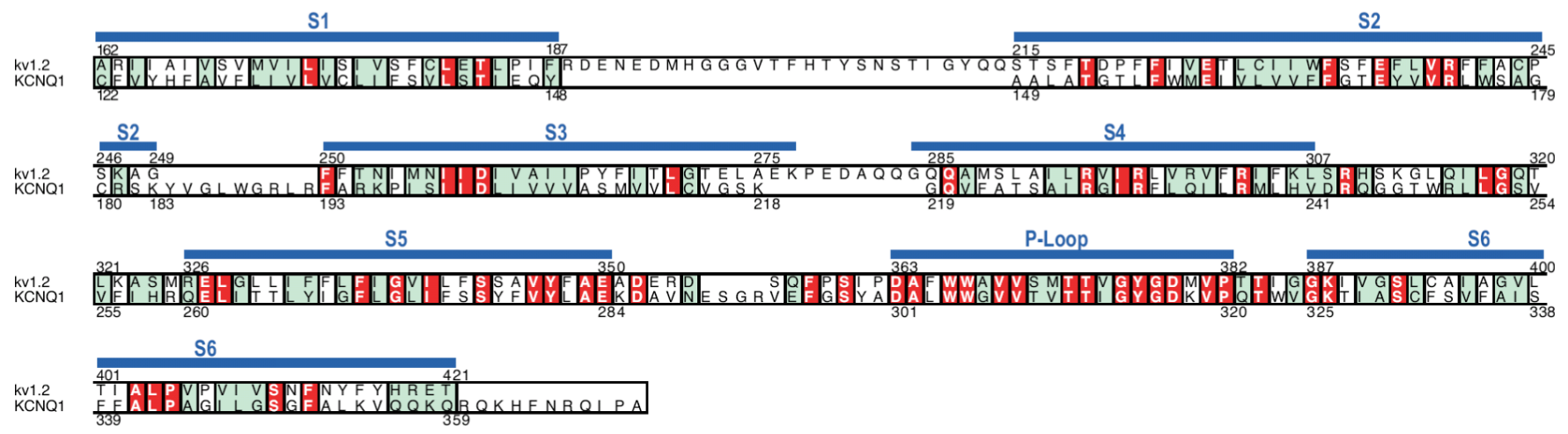

Figure 1.

Alignment of the human KCNQ1 channel domain sequence with that of the S1-S6 domain of the template, rat $\mathrm{K}_{\mathrm{v}} 1.2 . \mathrm{K}_{\mathrm{v}} 1.2$ secondary structure elements are indicated in blue, highlighting the fact that segmental insertions and deletions in the aligned sequences occur in regions between experimentally well-defined structural elements of the template. 


\section{Open}

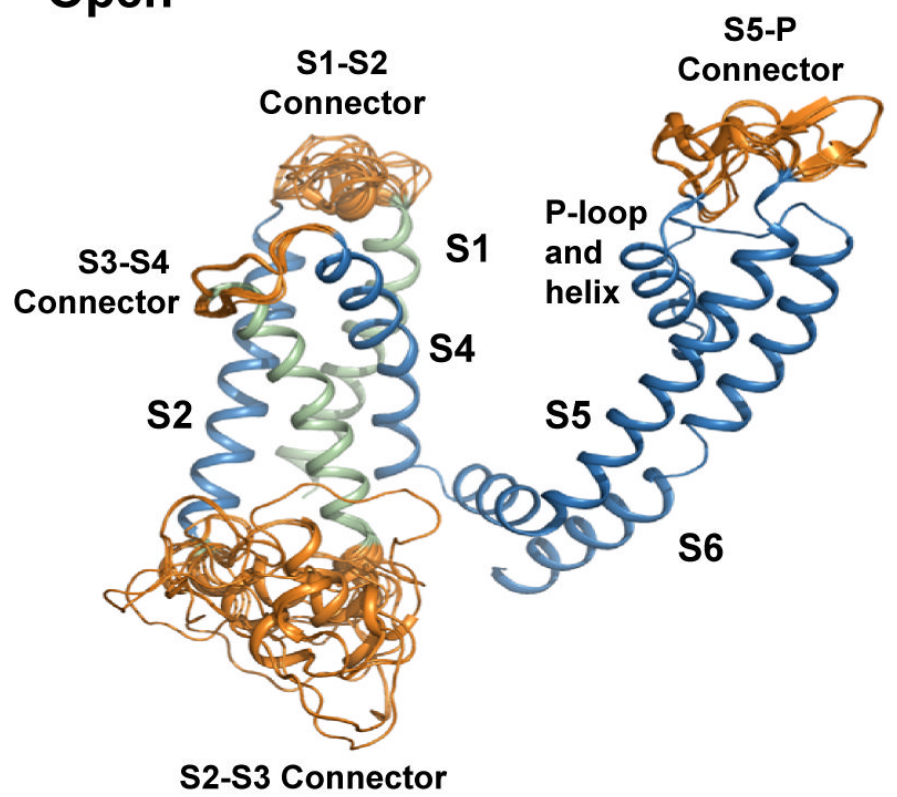

\section{Closed}

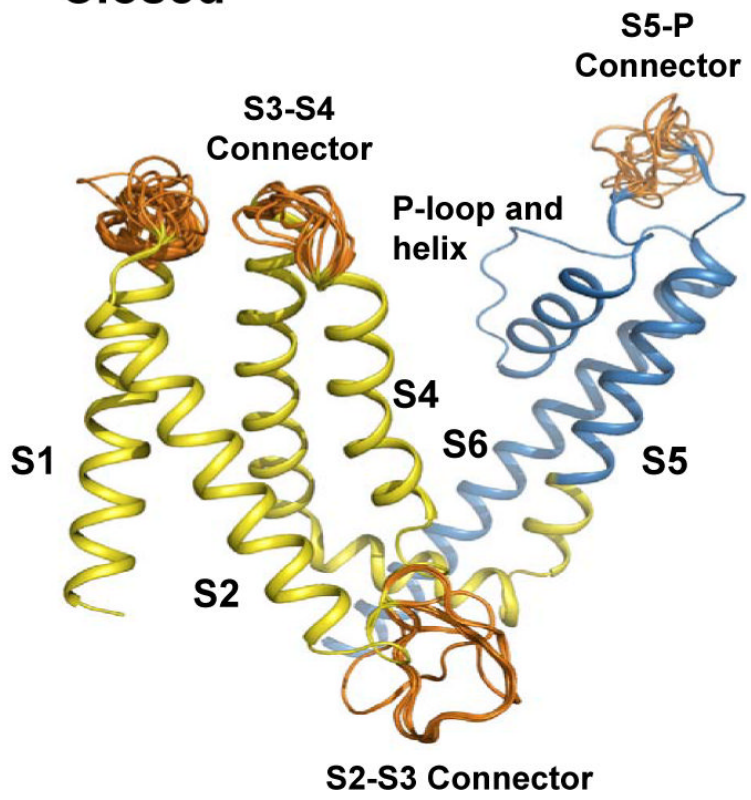

Figure 2.

Ensembles of the 20 lowest energy models for open and closed state KCNQ1 monomers. This highlights the implicit flexibility and/or conformational uncertainty for the loop segments of the models. For the open state, blue regions were derived from the $\mathrm{K}_{\mathrm{V}} 1.2$ crystal structure template (PDB entry 2A79). Green regions were derived from the crystal structure backbone coordinates for the S1 and S3 regions (that have no side chain electron density) using the side chain assignments worked out by Yarov-Yarovoy et al.(34) Orange regions were modeled de novo using Rosetta. For the closed state, blue regions were derived from the KcsA crystal structure (PDB entry 1K4C). Yellow regions were derived from the Yarov-Yaravoy et al. $\mathrm{K}_{\mathrm{V}} 1.2$ closed state model. Orange regions were modeled de novo using Rosetta, with the ensemble of all 20 models shown for completeness. The views that were chosen to illustrate each ensemble are independent of each other in order to more clearly illustrate the conformational diversity of the calculated loops. 

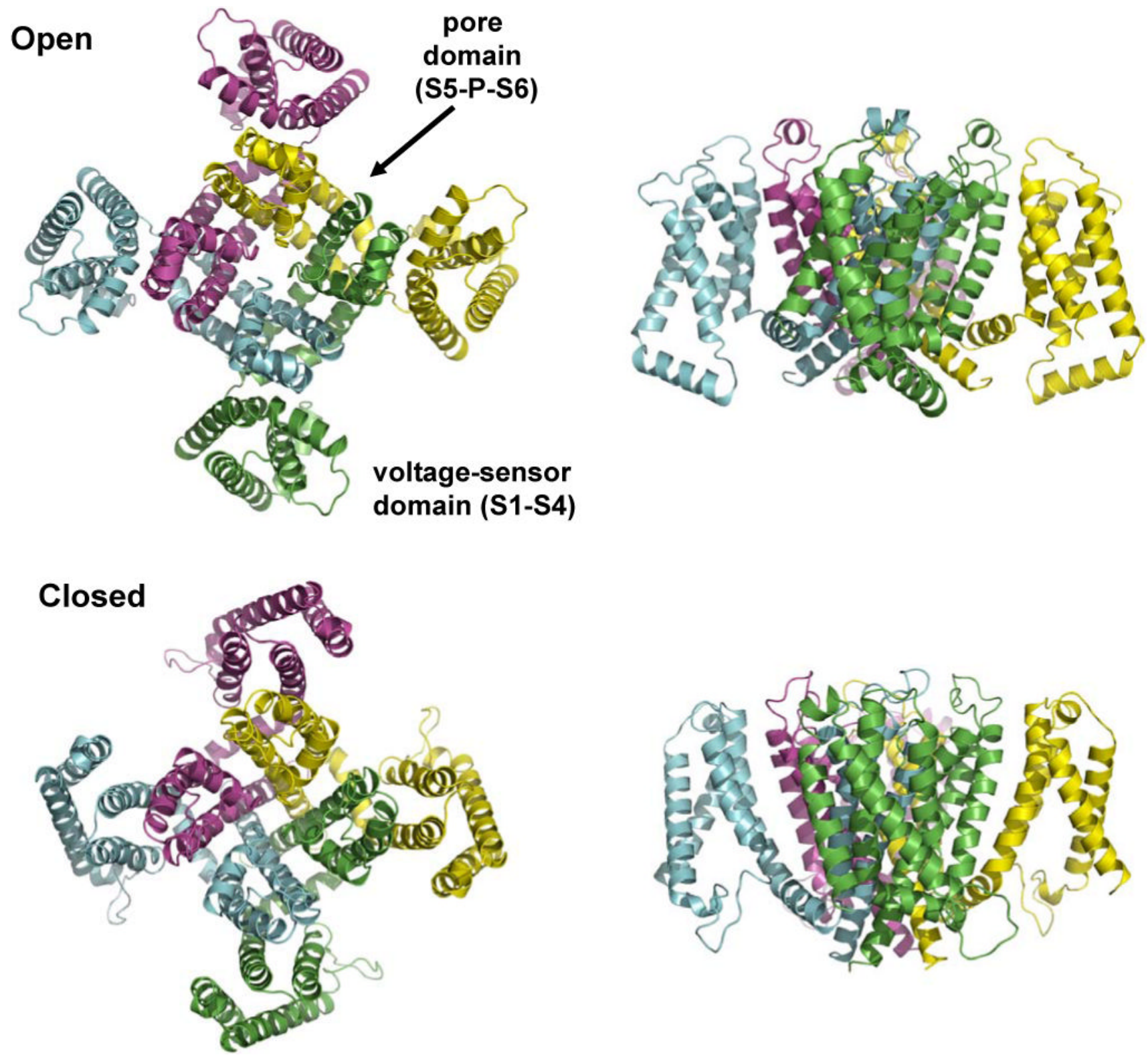

Figure 3.

Open and closed state models for the S1-S6 domain of KCNQ1. (3A.) Left. Extracellular view. Right. View from membrane plane. (3B.) Intracellular stereo view, with the atoms of Ser349 being highlighted in Van der Waals representation. 


\section{Sites for which point mutations lead to LQT1 and/or JNLS}

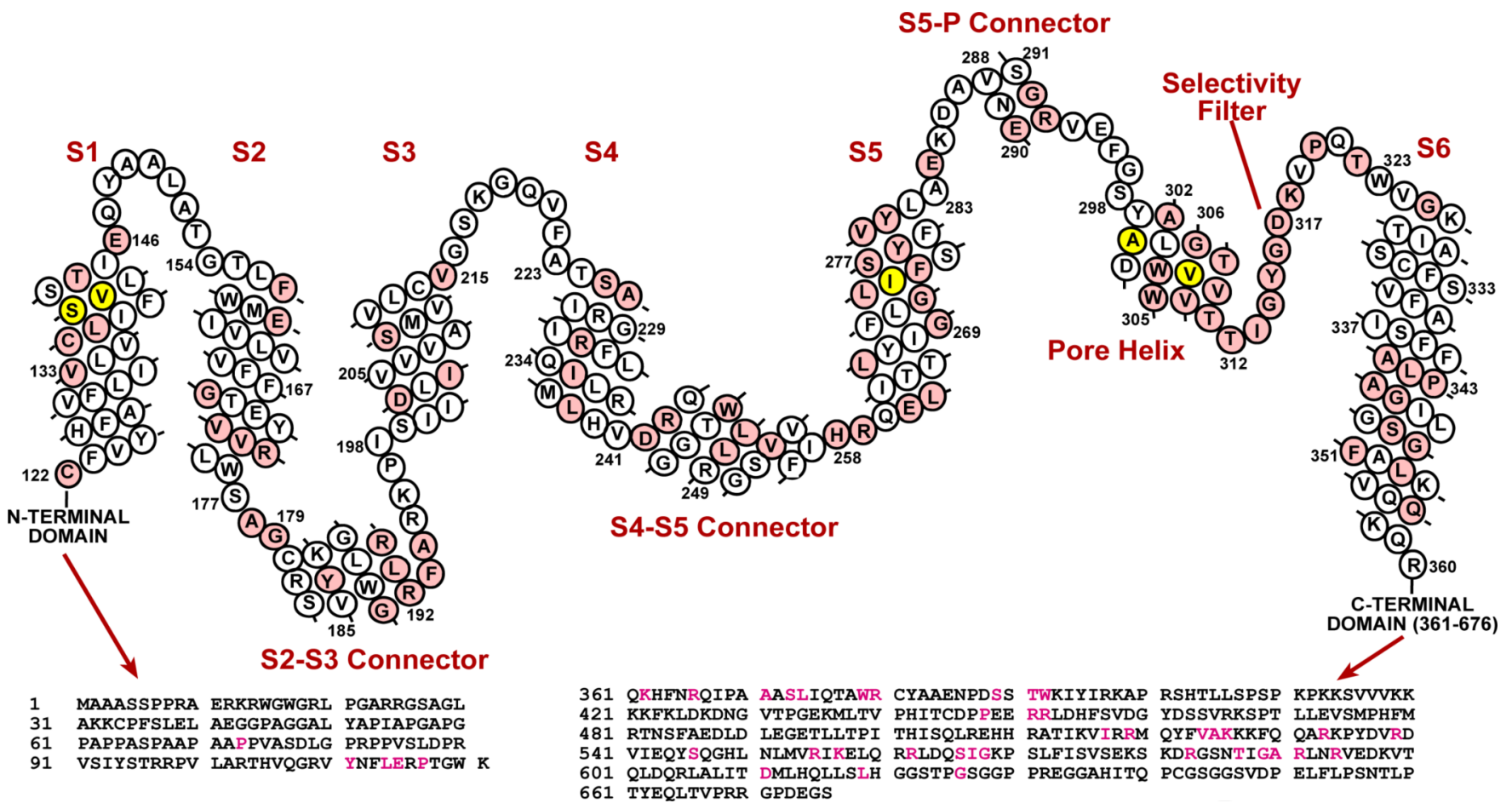

\section{Sites of gain-of-function mutations

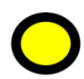

5-P Connector

361 OKHFNROIPA AASIIOTAWR CYAAENPDSS TTKIYIRKAP RSHTILSPSP KPKKSVVVKK I21 KKFKLDKDNG VTPGEKMLTV PHITCDPPEE RRLDHFSVDG YDSSVRKSPT LLEVSMPHM 541 VIEOYSOGHI NLMVRIKEIO RRIDOSIGKP SIFISVSEKS KDRGSNTIGA RLNRVEDKVT QIDQRLALIT DMLHQLISLH GGSTPGSGGP PREGGAHITO PCGSGGSVDP ELFIPSNTI

Figure 4.

Primary sequence and membrane topology for the S1-S6 domain of KCNQ1, with diseaseliked sites highlighted. The illustrated secondary structure is that of the lowest energy open state model. An annotated version of this figure is presented as the Supplementary Figure in the Supporting Information, which summarizes the differences between this KCNQ1 open state model and both the lowest energy KCNQ1 closed state model and the corresponding $\mathrm{K}_{\mathrm{V}} 1.2$ structures. 

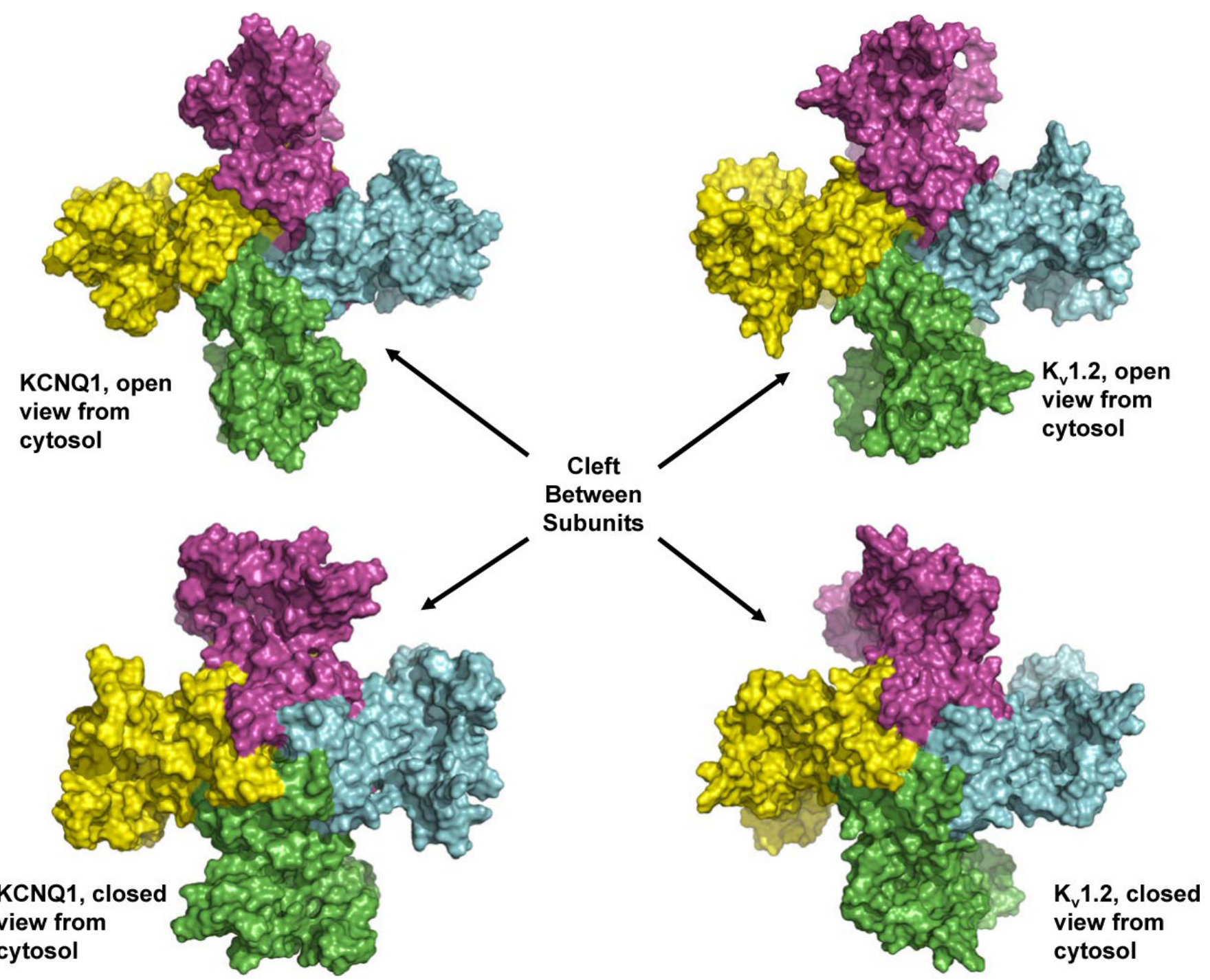

Figure 5.

Surface representations of the KCNQ1 models compared to the $\mathrm{K}_{\mathrm{v}} 1.2$ models developed of Yarov-Yarovy et al. (34) In all cases the view is from the cytosol. 

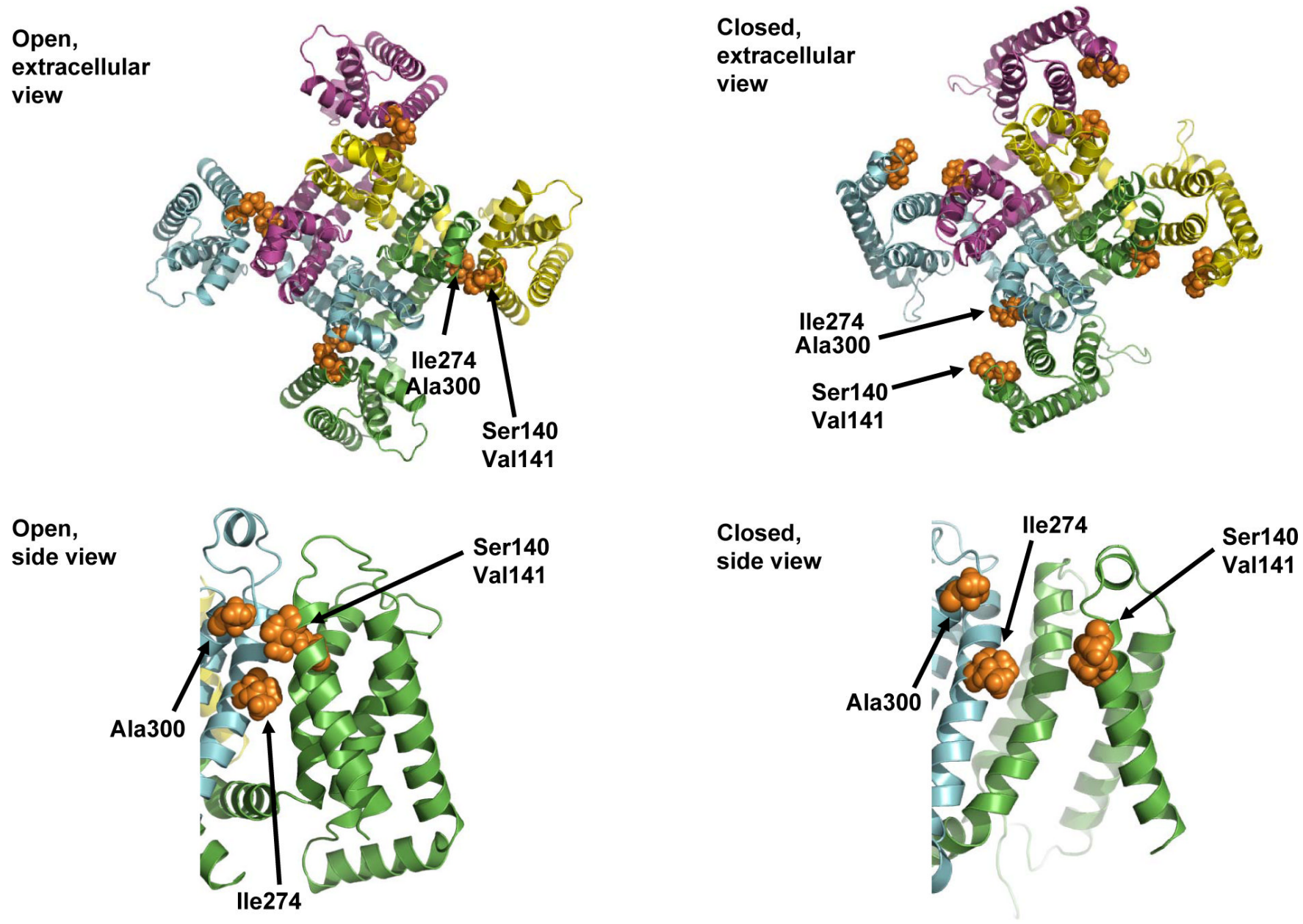

Figure 6.

Locations of KCNQ1 gain-of-function mutation Ser140Gly, Val141Met, Ile274Val, and Ala300Thr in the open and closed state models. The side chains highlighted in Van der Waals format are for the wild type residues at those positions. (Top) Extracellular view. (Bottom) View from membrane plane. 


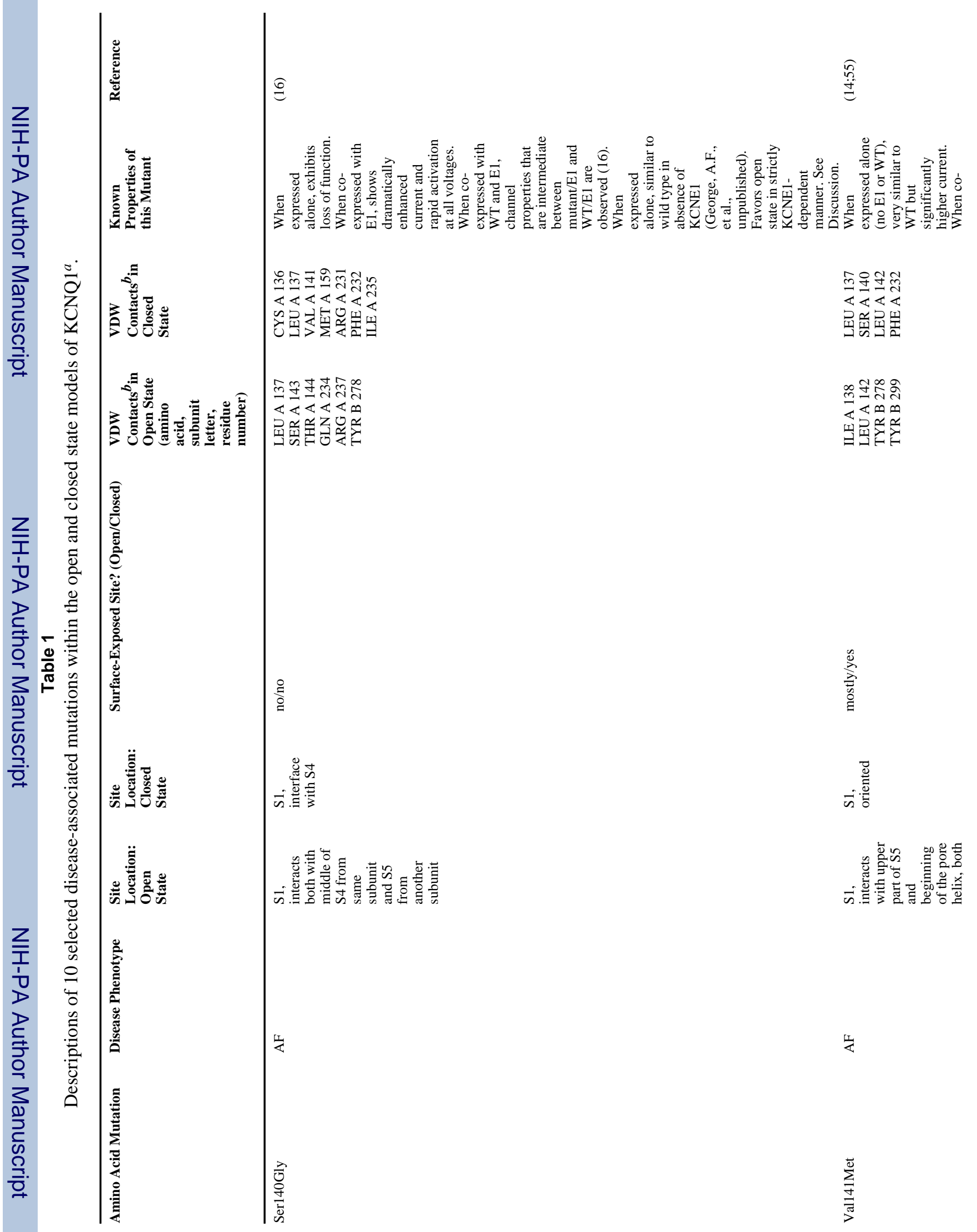

Biochemistry. Author manuscript; available in PMC 2008 December 11. 


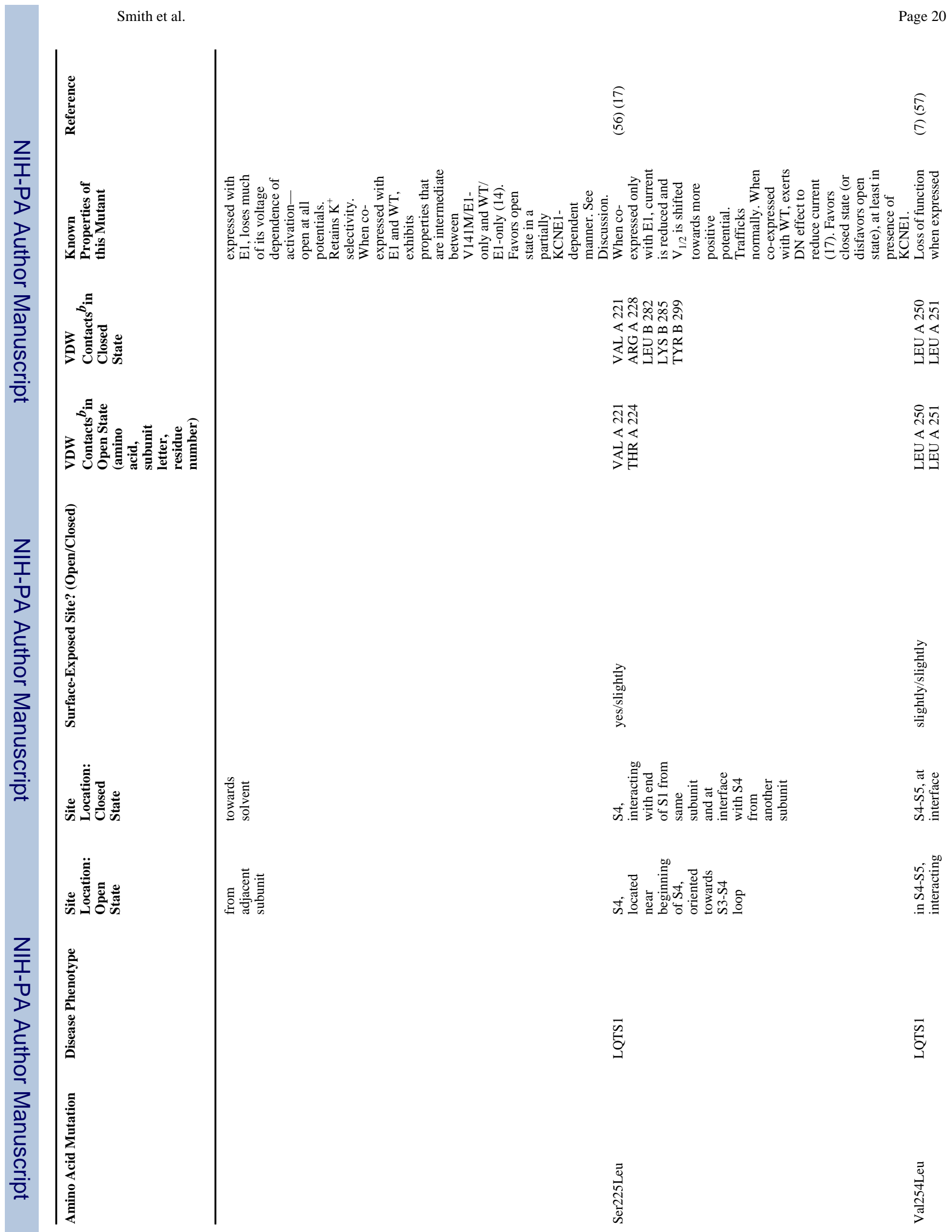

Biochemistry. Author manuscript; available in PMC 2008 December 11. 


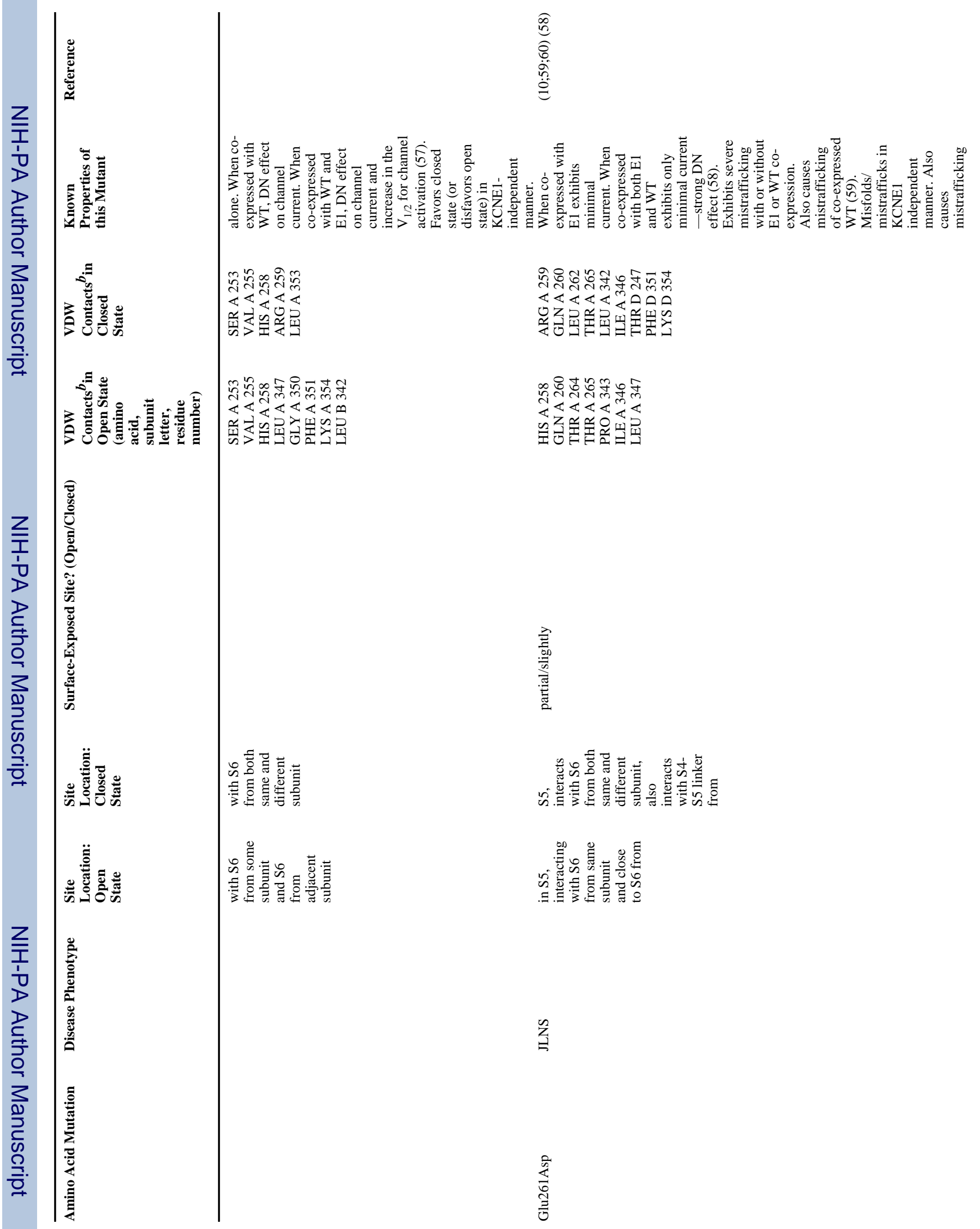




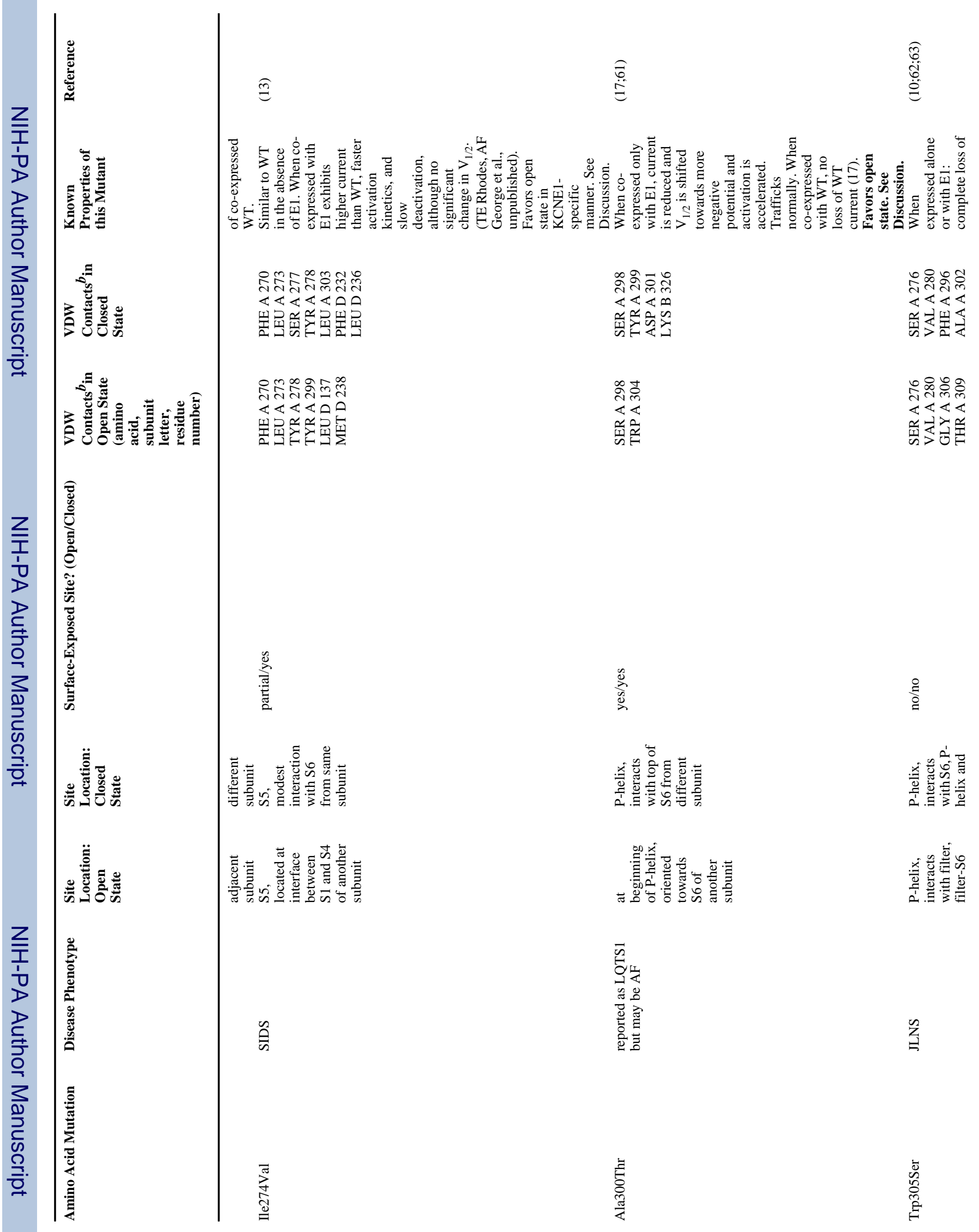

Biochemistry. Author manuscript; available in PMC 2008 December 11. 


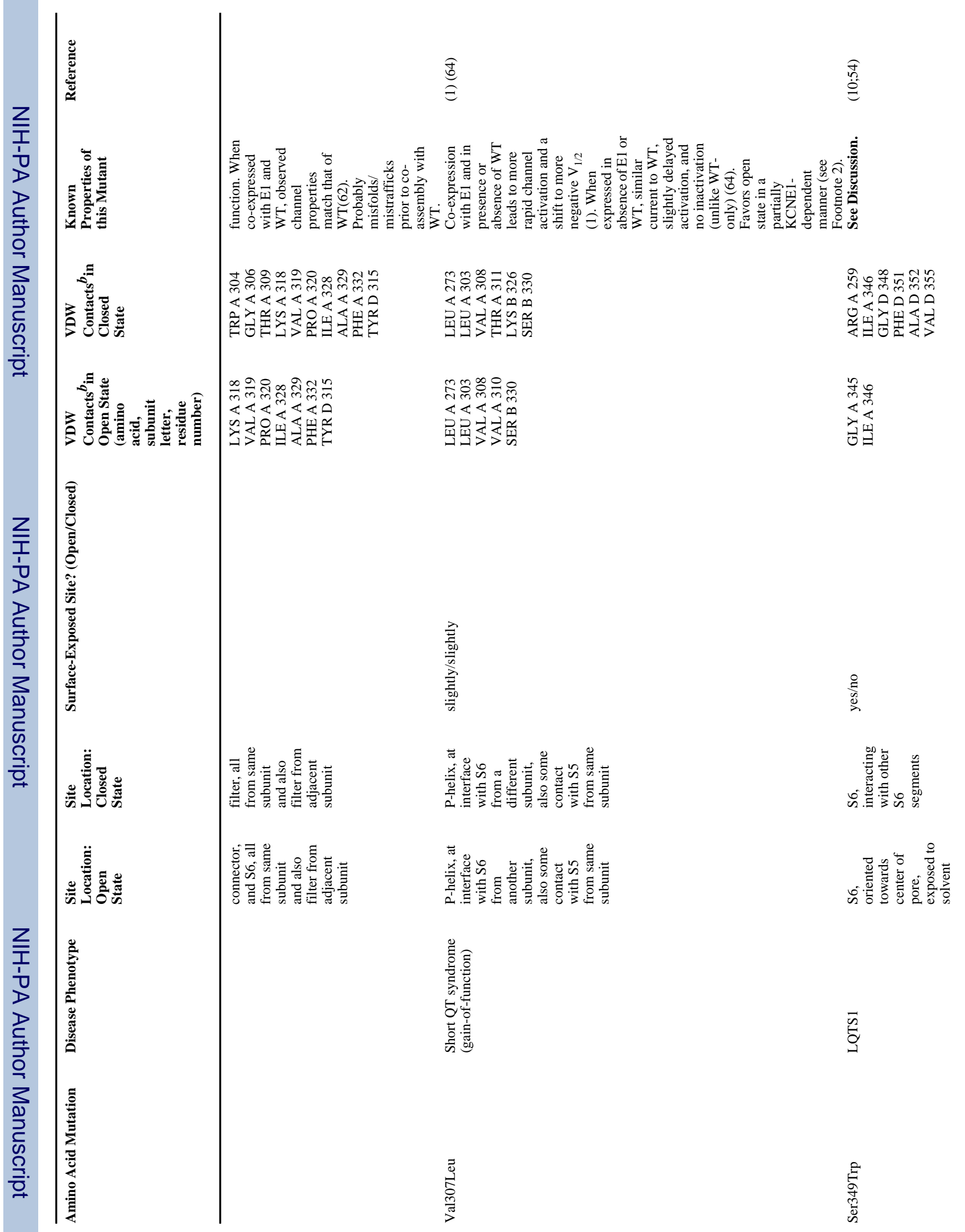




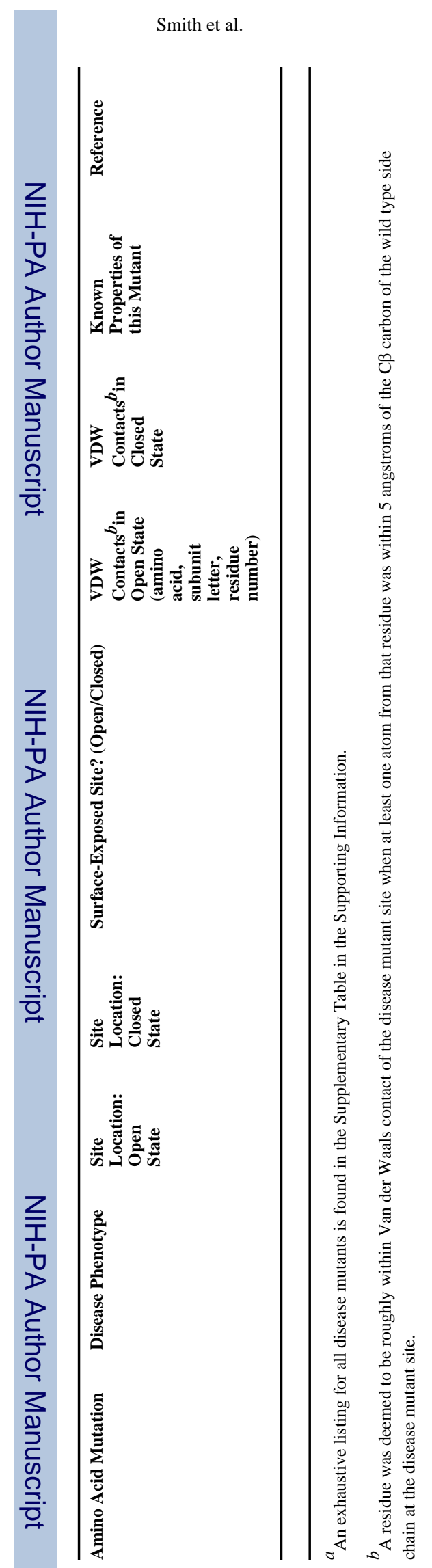

Page 24

Biochemistry. Author manuscript; available in PMC 2008 December 11. 